\title{
The relation between adverse childhood experiences and moral injury in the Canadian Armed Forces
}

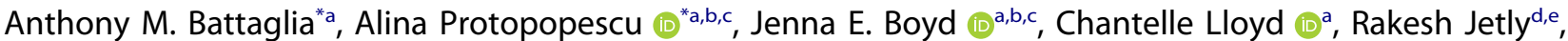 \\ Charlene O'Connor ${ }^{c, f}$, Heather K. Hood ${ }^{f, g}$, Anthony Nazarov $\mathbb{D i D}^{g, h}$, Shawn G. Rhind ${ }^{\mathrm{h}}$, Ruth A. Lanius (D) ${ }^{\mathrm{c}, \mathrm{ij}, \mathrm{k}}$ \\ and Margaret C. McKinnon ${ }^{\mathrm{b}, c, g}$
}

\begin{abstract}
aDepartments of Psychology, Neuroscience and Behaviour, McMaster University, Hamilton, ON, Canada; bMood Disorders Program, St. Joseph's Healthcare Hamilton, Hamilton, ON, Canada; cHomewood Research Institute, Guelph, ON, Canada; ${ }^{d}$ Department of National Defence, Government of Canada, Ottawa, ON, Canada; 'Department of Psychiatry, University of Ottawa, Ottawa, ON, Canada; ${ }^{\text {PProgram }}$ for Traumatic Stress Recovery, Homewood Health Centre, Guelph, ON, Canada; 9Psychiatry and Behavioural Neurosciences, McMaster

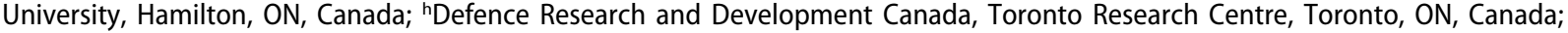
'Departments of Psychiatry, Western University, London, ON, Canada; 'Departments of Neuroscience, Western University, London, ON, Canada; kImaging Division, Lawson Health Research Institute, London, ON, Canada
\end{abstract}

\section{ABSTRACT}

Background: There is increasing evidence that moral injuries (Mls) may affect the mental health of Canadian Armed Forces (CAF) members and veterans. Despite knowledge suggesting that Mls are related to multiple negative mental health outcomes, including the onset of post-traumatic stress disorder (PTSD), it is unknown whether pre-traumatic variables, including the presence of childhood abuse, are related to Mls.

Objective: This study seeks to investigate the potential relationship between adverse childhood experiences and later onset MI in military members.

Methods: Thirty-three patients newly admitted to an inpatient unit for treatment of traumarelated disorders received a standardized self-assessment package, including the PTSD Checklist for DSM-5 (PCL-5), the Moral Injury Events Scale (MIES; adapted for the Canadian context), and the Adverse Childhood Experiences Questionnaire (ACE-Q), which is a retrospective measure of childhood abuse.

Results: Analyses revealed a significant relation between childhood emotional abuse and the presence of $\mathrm{Ml}$ in adulthood. Specifically, emotional abuse during childhood was correlated with total score on the MIES $(p=0.006)$ and with its two subscales, perceived betrayals $(p=0.022)$ and perceived transgressions $(p=0.016)$. These correlations remained significant when controlling for age and gender.

Conclusions: Among CAF members and veterans, childhood events are related to the presence of $\mathrm{Ml}$ during adulthood. These preliminary data are provocative in suggesting that emotional abuse during childhood may increase the likelihood of endorsing Ml during adult military service. Further work is needed to identify pre-traumatic variables that may serve to increase risk or enhance resilience to the development of MI in military members.

\section{La relación entre experiencias adversas en la infancia y daño moral en las Fuerzas Armadas Canadienses}

Antecedentes: Existe un aumento de la evidencia que los daños morales (Mls, por sus siglas en inglés) pueden afectar la salud mental de los miembros de las Fuerzas Armadas Canadienses (FAC) y veteranos. A pesar que el conocimiento sugiere que las Mls están relacionadas con múltiples consecuencias negativas en la salud mental, incluyendo el inicio del trastorno de estrés postraumático (TEPT), se desconoce si variables pre-traumáticas, incluyendo la presencia de abuso en la infancia, están relacionadas con Mls.

Objetivo: Este estudio busca investigar la relación potencial entre experiencias infantiles adversas y el posterior inicio de Mls entre los miembros militares.

Método: Treinta y tres pacientes nuevos admitidos a una unidad hospitalaria para tratamiento de los trastornos relacionados con trauma, recibieron un paquete estandarizado de auto-evaluación, incluyendo la lista de chequeo para TEPT del DSM-5 (PCL-5), la Escala de Eventos de Daño Moral (MIES por sus siglas en inglés, adaptada para el contexto canadiense) y el Cuestionario de Experiencias Adversas Condiciones Infantiles (ACE-Q por sus siglas en inglés).

Resultados: Los análisis revelaron una relación significativa entre abuso emocional en la infancia y la presencia de Ml en la adultez. Específicamente, el abuso emocional durante la infancia estuvo correlacionado con el puntaje total del MIES $(p=0.006)$ y con sus dos subescalas, percepción de traición $(p=0.022)$ y percepción de transgresiones $(p=0.016)$. Estas correlaciones permanecen significativas cuando se controlan por edad y sexo.
ARTICLE HISTORY

Received 27 April 2018 Revised 27 September 2018 Accepted 20 October 2018

\section{KEYWORDS}

Moral injury; post-traumatic stress disorder; adverse childhood experiences; military members; veterans; Canadian Armed Forces

\section{PALABRAS CLAVES}

Daño Moral; Trastorno de Estrés Postraumático; Experiencias Adversas Durante la Infancia; miembros militaresveteranos; Fuerzas Armadas Canadienses

关键词

精神伤害; 创伤后应激障 碍; 负性童年经历; 军人退 伍军人; 加拿大武装部队

\section{HIGHLIGHTS}

- Prior research suggests that adverse childhood experiences influence the development of adult posttraumatic stress disorder (PTSD) in civilian and military populations. - Moreover, research suggests a relation between PTSD and moral injury (MI) in military populations. - The current study finds that experiencing childhood emotional abuse is related to the presence of $\mathrm{Ml}$ during adult military service, even after controlling for age and gender.

CONTACT Margaret C. McKinnon mmckinno@stjoes.ca Department of Psychiatry and Behavioural Neurosciences, McMaster University, 100 West 5th Street, Hamilton, ON, Canada

*Shared first authorship

(c) 2019 The Author(s). Published by Informa UK Limited, trading as Taylor \& Francis Group.

This is an Open Access article distributed under the terms of the Creative Commons Attribution-NonCommercial License (http://creativecommons.org/licenses/by-nc/4.0/) which permits unrestricted non-commercial use, distribution, and reproduction in any medium, provided the original work is properly cited. 
Conclusiones: Entre los miembros y veteranos FAC, los eventos en la infancia están relacionados con la presencia de $\mathrm{Ml}$ durante la adultez. Estos datos preliminares son provocativos en sugerir que el abuso emocional durante la infancia puede incrementar la posibilidad de refrendar Ml durante el servicio militar en la adultez. Es necesaria más investigación para identificar las variables pre-traumáticas que pueden servir para incrementar el riesgo o aumentar la resiliencia a desarrollar $\mathrm{Ml}$ entre los miembros militares.

\section{加拿大武装部队的负性童年经历与精神伤害之间的关系}

背景：越来越多的证据表明，精神伤害（moral, injuries, MIs）可能会影响加拿大武装部 队 (CAF) 成员和退伍军人的心理健康。尽管证据表明精神伤害与多种消极心理健康结 果有关, 包括创伤后应激障碍 (PTSD) 的发病, 但还不清楚精神伤害是否与创伤前变量 （包括经历童年虐待）相关。

目的：本研究旨在探讨军人中负性童年经历与随后出现的精神伤害之间的潜在关系。

方法：标准化的自评工具包对新入住病房治疗创伤相关疾病的33名患者进行评估, 包括 PCL-5, 精神伤害事件量表 (MIES; 适用于加拿大人) 和负性童年经历问卷 (ACE-Q)。

结果 : 分析显示儿童情绪虐待与成年期精神伤害之间存在显著关系。具体而言, 童年情 感虐待与MIES的总得分 $(p=0.006)$ 及其两个分量表: 感知到的背叛 $(p=0.022)$ 和感知 到的违规 $(p=0.016)$ 相关。在控制年龄和性别之后，这些相关性仍然显著。

结论：在CAF成员和退伍军人中，童年事件与成年期MI有关。这些初步数据具有启发性， 表明童年时期的情感虐待可能会增加成人服役期间精神伤害的可能性。但还需深入的研 究以识别军人中可能会增加MI 风险或增强抵御MI能力的创伤前变量。

\section{Introduction}

The modern era of unconventional and asymmetric warfare has changed the landscape of combat; illdefined enemies, morally ambiguous objectives, and strict rules of engagement, including those requiring soldiers to bear passive witness to atrocities, may result in combatants experiencing moral injury (MI) (Jordan, Eisen, Bolton, Nash, \& Litz, 2017; Thompson \& Jetly, 2014). MI can occur through experiences of betrayal by military leadership (e.g. a military physician following an order to triage military members over gravely injured civilians) and/or transgressions: perpetrating, observing, failing to prevent, or learning about perceived unethical acts (e.g. witnessing or contributing to civilian deaths) (Litz et al., 2009; Shay, 1991).

Increasing evidence suggests that experiencing morally injurious events may be linked with adverse mental health consequences (e.g. Currier, Holland, \& Mallott, 2015; Nazarov, Fikretoglu, Liu, Thompson, \& Zamorski, 2018; Nazarov et al., 2015; Watkins, Sudom, \& Zamorski, 2016). Indeed, a 2018 meta-analysis linked MI to a host of negative mental health outcomes, including post-traumatic stress disorder (PTSD), major depressive disorder (MDD), hostility, and suicidality in both military and civilian populations (Williamson, Stevelink, \& Greenberg, 2018). Moreover, MI has been associated with other adverse outcomes including perceived loss of trust, self-deprecation, spiritual/existential crises, and difficulties with social functioning and interpersonal relationships (Vargas, Hanson, Kraus, Drescher, \& Foy, 2013).

Within the Canadian Armed Forces (CAF), evidence suggests that MIs also may affect the mental health of military personnel and veterans (Nazarov et al., 2018; Watkins et al., 2016). Over half of deployed personnel reported exposure to at least one potentially morally injurious event, which served as an independent risk factor for PTSD and MDD (Nazarov et al., 2018). Critically, psychological dysfunction, such as PTSD and MDD, within the CAF has been associated with heightened levels of disability (Hoge et al., 2005; Weeks, Garber, \& Zamorski, 2016), and negative occupational outcomes (e.g. attrition, discharge) (Boulos \& Zamorski, 2016; Hoge, Auchterlonie, \& Milliken, 2006; Hoge et al., 2005). Given this linkage, it is probable that identifying factors related to the onset of MI will have a positive impact on the occupational outcomes (e.g. attrition and discharge) of armed forces personnel in Canada and abroad.

Exposure to adverse childhood experiences (ACEs) (Cook et al., 2017; Litz et al., 2009) may influence the onset of MI among CAF members. ACEs include events such as neglect or exposure to physical, emotional, and/or sexual abuse (Cook et al., 2017). Approximately $33.1 \%$ of Canadians are estimated to have experienced childhood physical abuse, sexual abuse, and/or exposure to interpersonal violence, with significantly higher rates (i.e. 47.7\%) reported among Canadian military members (Afifi et al., 2016). This connection between ACEs and voluntary military enlistment is thought to stem, in part, from the somewhat lower socioeconomic status (SES) of military enrollees (Lutz, 2008), with lower SES linked previously to increased exposure to ACEs (Bank, 2013). Furthermore, it has been suggested that individuals exposed to childhood trauma may voluntarily join the military in greater numbers to escape the adversity encountered in their homes (Blosnich, Dichter, Cerulli, Batten, \& Bossarte, 2014), improving 
their life circumstances through the career and education opportunities available within the military (Afifi et al., 2016). Critically, both low SES and exposure to ACEs have been identified as risk factors for the development of combat-related PTSD (Xue et al., 2015).

Moreover, similarly to exposure to morally injurious experiences, ACEs have also been linked to a wide range of negative psychological outcomes among military members (e.g. Afifi et al., 2016; Lang et al., 2008; Skopp, Luxton, Bush, \& Sirotin, 2011). Specifically, a dose-response relation (e.g. Iversen et al., 2008) links ACEs and negative mental health outcomes in both male (Katon et al., 2015) and female (Lang et al., 2008) military members. Notably, higher rates of exposure to ACEs among Canadian military members are associated not only with heightened suicidal ideation, suicide, and suicide attempts (Afifi et al., 2016; Skopp et al., 2011), but also with higher perceived needs for mental health care and higher mental health-care service utilization (Turner et al., 2017). ACEs have also been associated with the development of PTSD among military members, even when controlling for combat exposure (Iversen et al., 2008, 2007; LeardMann, Smith, \& Ryan, 2010). For example, in a prospective study, the presence of past ACEs was found to be a stronger predictor of PTSD and depression outcomes than combat exposure (Cabrera, Hoge, Bliese, Castro, \& Messer, 2007). In a separate military sample, when controlling for combat trauma, ACEs statistically increased the likelihood of poor health, fatigue, severe substance abuse, and self-harm (Iversen et al., 2007). Within a CAF sample, exposure to ACEs and deploymentrelated traumatic experiences (DRTEs) were associated with an increased odds ratio of developing mood and anxiety disorders, such as PTSD, when compared to individuals in the same sample who were not exposed to either of these events, or who were exposed to DRTEs but not to ACEs (Sareen et al., 2013).

ACEs and MI may exert a similar influence on an individual's appraisals of him or herself, others, and the world (Cook et al., 2017; Litz et al., 2009; Vargas et al., 2013). Specifically, both MI and ACEs may alter existing schemas that the world is benevolent and meaningful, that others are trustworthy, and that the self is worthy (Cook et al., 2017; Litz et al., 2009; Vargas et al., 2013). Self-handicapping behaviours, including shunning positive experiences and social withdrawal, have been related to both ACEs and MI (Cook et al., 2017; Litz et al., 2009; Vargas et al., 2013), where sense of self may be altered by low self-esteem, shame, and guilt (Cook et al., 2017; Litz et al., 2009). As such, exposure to childhood traumas may 'prime' military members to $\mathrm{MI}$, by setting a context that is already characterized by low self-worth, shame, and ongoing guilt about past experiences (e.g. the belief that oneself is 'bad'), which together may contribute to the potential onset of a MI.
Despite the potentially additive effects of ACEs and MIs on an individual's beliefs about themselves, others, and the world, and knowledge of negative mental health outcomes that can follow both MI and ACEs among Canadian military members and veterans, it remains unknown whether exposure to ACEs is related to the endorsement of MI during adult military service. Accordingly, we sought to examine this relation in a sample of CAF members and veterans. Data were analysed as part of a retrospective review of admission data collected in patients admitted to an inpatient psychiatric unit for treatment of PTSD and trauma-related disorders. Here, we hypothesized that exposure to ACEs, as measured by the Adverse Childhood Experiences Questionnaire (ACE-Q) (Felitti et al., 1998), would be associated with elevated levels of MI among this sample. Following a study by Merrick et al. (2017), this relation was examined for both the total ACE-Q score and individual ACE-Q items reflecting different types of ACE (e.g. physical neglect and emotional abuse).

\section{Methods}

\subsection{Participants and procedure}

As part of routine clinical assessment, inpatients admitted to the Program for Traumatic Stress Recovery (PTSR) at Homewood Health Centre in Guelph, ON, Canada, between 22 May 2015 and 30 June 2016 completed a comprehensive standardized self-report assessment battery. Patients were admitted to this unit based on presumed exposure to traumatic events. The Homewood Research Ethics Board approved a retrospective medical chart review of an anonymized version of these data (REB 17-03). Of the 201 individuals who underwent assessment over this period, 43 participants identified as being veterans or active CAF personnel.

Demographic information (i.e. gender, age, marital status, education, and income) was requested from the Resident Assessment Instrument - Mental Health Assessment (RAI-MH), an Ontario Ministry of Health and Long-Term Care mandated measure for collection of clinical and administrative data. Participants were excluded from the analyses based on missing or incomplete data ( $n=5$; list-wise deletion based on missing data from any variable in the analysis), multiple admissions $(n=2)$, and joint first responder status $(n=3)$, leaving a final sample of 33 participants. Symptom severity was assessed using the PTSD Checklist for DSM-5 (PCL-5) (Weathers et al., 2013). The clinical and demographic characteristics of the study sample are reported in Table 1. A subset of participants from the current study (samples not identical; based on available data) also appears in other reports, which examine the relations between dissociation among military members, veterans, and first responders, and 
Table 1. Demographic characteristics of participants $(N=33)$.

\begin{tabular}{lcc}
\hline Variable & $n$ & \% of sample \\
\hline Gender & 29 & \\
Male & 4 & 87.9 \\
Female & & 12.1 \\
Marital status & 4 & 12.1 \\
Never married & 16 & 48.5 \\
Married/common law & 3 & 9.1 \\
Living with significant other & 0 & 0.0 \\
Widowed & 7 & 21.2 \\
Separated & 3 & 9.1 \\
Divorced & & \\
Highest level of education attained & 0 & 0 \\
No schooling & 1 & 3.0 \\
8th grade or less & 4 & 12.1 \\
9-11 grades & 9 & 27.3 \\
High school & 5 & 15.2 \\
Tech/trade school & 7 & 21.2 \\
Some college/university & 5 & 15.2 \\
Diploma/bachelor's & 2 & 6.1 \\
Graduate & 0 & 0.0 \\
Unknown & & \\
Income & 13 & 39.4 \\
Employed & 1 & 3.0 \\
Unemployed (El) & 11 & 33.3 \\
Pension & 9 & 27.3 \\
Disability & 1 & 3.0 \\
Other income & 4 & 12.1 \\
No income & Mean & $S D$ \\
\hline$\quad$ & 44.7 & 10.3 \\
\hline Age at intake (years) & & \\
\hline & & \\
\hline & & \\
\hline
\end{tabular}

functional outcomes (Boyd et al., 2018) and between MI and emotion dysregulation in military members and veterans (Protopopescu et al., submitted).

\subsection{Materials}

\subsubsection{Adverse Childhood Experiences}

Questionnaire (ACE-Q) (Felitti et al., 1998; Merrick et al., 2017)

The ACE-Q is a seven-item self-report, retrospective measure that assesses commonly experienced ACEs (Felitti et al., 1998). Here, we administered an expanded 10-item version of this scale, similar to Merrick et al. (2017), with the exception that spanking was not included. Whereas the majority of studies involving the ACE-Q report a cumulative index (i.e. total ACE score) that combines ACE items assessing childhood abuse and neglect (emotional, physical, and sexual abuse, and emotional and physical neglect) with those assessing household dysfunction (separation/divorce of parents, domestic violence, and substance abusing, mentally ill, or incarcerated family members), here we relied on a scoring approach described by Merrick et al. (2017). Specifically, each of the 10 items was scored on a dichotomous scale of either 0 (no) or 1 (yes), and responses were analysed for each item and for the cumulative score.

\subsubsection{PTSD Checklist for DSM-5 (PCL-5) (Weathers et al., 2013)}

The PCL-5 is a 20 -item, self-report questionnaire assessing the severity of PTSD symptoms following the
Diagnostic and Statistical Manual for Mental Health Disorders, Fifth Edition (DSM-5) (American Psychiatric Association, 2013) criteria of intrusive symptoms, avoidance, negative alterations in mood and cognition, and alterations in arousal and reactivity (Weathers et al., 2013). Items are scored on a five-point Likert scale, with total scores ranging from 0 to 80 ; greater scores are associated with greater symptom severity (Weathers et al., 2013). The scale demonstrates high internal consistency $(\alpha=0.94)$ and good test-retest reliability $(r=0.82)$ (Blevins, Weathers, Davis, Witte, \& Domino, 2015).

\subsubsection{Moral Injury Events Scale (MIES) (Nash et al., 2013)}

The MIES is a nine-item, self-report measure intended to assess exposure to $\mathrm{MI}$ in military populations along two dimensions: perceived transgressions and perceived betrayals (Nash et al., 2013). In the present study, the MIES was modified for the Canadian context (Nash et al., 2013). Perceived transgressions include witnessing or committing acts, or failing to act in ways that violate one's internal moral code (Nash et al., 2013). The MIES assesses whether respondents perceive exposure to moral transgressions and whether they are distressed by these occurrences (Nash et al., 2013). Perceived betrayals may relate to leaders, fellow soldiers, or those outside the military (Nash et al., 2013). Each item is scored on a six-point Likert scale, with summed scores ranging from 9 to 54; higher scores indicate greater severity of MI (Nash et al., 2013). This scale has excellent internal consistency, with a Cronbach's alpha of 0.9, and good temporal stability (Nash et al., 2013).

\subsection{Statistical analysis}

SPSS version 23.0 (IBM Corp., Armonk, NY, USA) was used to conduct all analyses. Owing to nonnormality of the data distributions and outliers, non-parametric tests were used to analyse the data. Spearman's (rho) correlation $\left(r_{\mathrm{s}}\right)$ was used to assess any associations between the ranked continuous overall scores and subscale scores on the three self-report measures. Following this, rank-biserial $\left(r_{\mathrm{bs}}\right)$ correlations were calculated between individual dichotomous ACE items and the ranked overall/subscale scores on the MIES. Spearman's partial correlations and rank-biserial partial correlations were used to control for age and gender. Statistical significance was set at $\alpha=0.05$ for this pilot investigation.

\section{Results}

\subsection{Sample demographics}

The mean age of the sample was 44.7 years $(S D=10.3)$. The greatest proportions of individuals were male 
(87.9\%), were married or in a common-law relationship (48.5\%), had obtained a high school education (27.3\%), and were currently receiving income from employment (39.4\%). The demographic characteristics of the study sample are summarized in Table 1.

\subsection{Descriptive statistics}

The mean, standard deviation, and range of each of the scales and their corresponding subscales are summarized in Table 2, along with the frequencies of each reported ACE-Q item. The mean ACE-Q total score for this sample was $3.0(S D=2.5)$, with emotional abuse reported most frequently $(48.5 \%)$ and having an incarcerated family member reported least frequently (9.1\%). The mean total score among the sample on the PCL-5 was $57.9(S D=14.5)$, falling well above the clinical cut-off of 33 for a provisional diagnosis of PTSD (Weathers et al., 2013). Finally, the mean score on the MIES was $38.0(S D=12.7)$ (measure range of $0-54$; sample range of $10-54$ ), pointing to the presence of MI in this inpatient sample of trauma-exposed participants.

Table 2. Summary of ACE-Q, PCL, and MIES scores.

\begin{tabular}{lccc}
\hline Scale & Mean (SD) & Min. & Max. \\
\hline ACE-Q total & $3.0(2.5)$ & 0 & 9 \\
PCL total & $57.9(14.5)$ & 14 & 79 \\
$\quad$ PCL intrusions & $14.2(5.1)$ & 2 & 20 \\
PCL avoidance & $6.1(1.9)$ & 1 & 8 \\
PCL cognition/mood & $20.9(5.1)$ & 4 & 28 \\
PCL reactivity & $16.7(4.4)$ & 7 & 23 \\
MIES total & $38.0(12.7)$ & 10 & 54 \\
$\quad$ MIES betrayal & $12.7(4.8)$ & 3 & 18 \\
$\quad$ MIES transgressions & $25.3(9.2)$ & 6 & 36 \\
\hline ACE-Q item & Yes $(\%$ endorsing) & No (\% endorsing) & \\
\hline Emotional abuse & $16(48.5)$ & $17(51.5)$ & \\
Physical abuse & $13(39.4)$ & $20(60.6)$ & \\
Sexual abuse & $8(24.2)$ & $25(75.8)$ & \\
Emotional neglect & $9(27.3)$ & $24(72.7)$ & \\
Physical neglect & $7(21.2)$ & $26(78.8)$ & \\
Separation/divorce & $14(42.4)$ & $19(57.6)$ & \\
Domestic violence & $7(21.2)$ & $26(78.8)$ & \\
Substance abuse & $11(33.3)$ & $22(66.7)$ & \\
Mental illness & $10(30.3)$ & $23(69.7)$ & \\
Incarceration & $3(9.1)$ & $30(90.9)$ & \\
\hline ACE-Q Adverse & Exildhod &
\end{tabular}

ACE-Q, Adverse Childhood Experiences Questionnaire; PCL, PTSD Checklist for DSM-5; MIES, Moral Injury Events Scale.

\subsection{Correlations between ACE-Q, PCL-5, and MIES}

There was a significant correlation between the MIES betrayals subscale and the PCL avoidance subscale $\left(r_{\mathrm{s}}=0.360, p=0.039\right)$, and between the MIES betrayals subscale and the PCL subscale negative alterations in cognition $/ \mathrm{mood} \quad\left(r_{\mathrm{s}}=0.372\right.$, $p=0.033)$. Although the correlations were not significant, the relations between the MIES betrayals subscale and the PCL total score $\left(r_{\mathrm{s}}=0.343\right.$, $p=0.051)$, as well as the MIES total score and the PCL avoidance subscale $\left(r_{\mathrm{s}}=0.321, p=0.068\right)$, showed a trend towards significance. There were no significant correlations between total scores on the MIES, PCL, and ACE-Q (Table 3).

Even after controlling for age and gender, the correlations between the MIES betrayals subscale and the PCL avoidance subscale $\left(r_{\mathrm{s}}=0.366, p=0.043\right)$, and between the MIES betrayals subscale and the PCL subscale negative alterations in cognition $/ \operatorname{mood}\left(r_{\mathrm{s}}=0.376\right.$, $p=0.037)$ remained significant. Although still not significant, the relations between the MIES betrayals subscale and the PCL total score $\left(r_{\mathrm{s}}=0.344, p=0.058\right)$, and between the MIES total score and the PCL avoidance subscale $\left(r_{\mathrm{s}}=0.315, p=0.085\right)$, continued to trend towards significance.

\subsection{ACE-Q items correlated with MIES}

We next conducted an analysis of individual ACE-Q items and MIES scores. Critically, emotional abuse, as measured by the ACE-Q, was significantly positively correlated with MIES total score $\left(r_{\mathrm{bs}}=0.469\right.$, $p=0.006)$, and with the two subscales, betrayals $\left(r_{\mathrm{bs}}=0.397, p=0.022\right)$ and transgressions $\left(r_{\mathrm{bs}}=0.415, p=0.016\right)$. Detailed statistics are presented in Table 4.

After controlling for age and gender, emotional abuse remained positively correlated with MIES total score $\left(r_{\mathrm{bs}}=0.500, p=0.006\right)$, and with the MIES subscales, betrayals $\left(r_{\mathrm{bs}}=0.451, p=0.022\right)$ and transgressions $\left(r_{\mathrm{bs}}=0.429, p=0.016\right)$.

Table 3. Spearman's rank (rho) correlations between ACE-Q, PCL-5, and MIES.

\begin{tabular}{|c|c|c|c|c|c|c|c|c|}
\hline & $\begin{array}{l}\text { ACE } \\
\text { total }\end{array}$ & $\begin{array}{l}\mathrm{PCL} \\
\text { total }\end{array}$ & $\begin{array}{c}\mathrm{PCL} \\
\text { intrusions }\end{array}$ & $\begin{array}{c}\mathrm{PCL} \\
\text { avoidance }\end{array}$ & $\begin{array}{l}\text { PCL cognition/ } \\
\text { mood }\end{array}$ & $\begin{array}{c}\mathrm{PCL} \\
\text { reactivity }\end{array}$ & $\begin{array}{c}\text { MIES } \\
\text { transgressions }\end{array}$ & $\begin{array}{c}\text { MIES } \\
\text { betrayals }\end{array}$ \\
\hline PCL total & 0.100 & & & & & & & \\
\hline PCL intrusions & 0.120 & $0.818^{* *}$ & - & & & & & \\
\hline PCL avoidance & -0.084 & $0.626 * *$ & $0 . \overline{563} * *$ & - & & & & \\
\hline PCL cognition/mood & 0.059 & $0.901 * *$ & $0.638^{* *}$ & $0.510 * *$ & - & & & \\
\hline PCL reactivity & 0.105 & $0.882^{* *}$ & $0.627^{* *}$ & $0.459 * *$ & $0 . \overline{443} *$ & & & \\
\hline MIES transgressions & 0.224 & 0.178 & -0.032 & 0.170 & 0.210 & $0 . \overline{103}$ & - & \\
\hline MIES betrayals & 0.086 & $0.343^{a}$ & 0.137 & $0.360 *$ & $0.372 *$ & 0.260 & $0 . \overline{519} * *$ & - \\
\hline MIES total & 0.154 & 0.282 & 0.065 & 0.281 & $0.321^{b}$ & 0.187 & $0.901 * *$ & $0 . \overline{787} * *$ \\
\hline
\end{tabular}

ACE, Adverse Childhood Experiences Questionnaire; PCL, PTSD Checklist for DSM-5; MIES, Moral Injury Events Scale. ${ }^{* *}$ Correlation is significant at the 0.01 level (two-tailed).

${ }^{*}$ Correlation is significant at the 0.05 level (two-tailed).

${ }^{a}$ Correlation is trending at $p=0.051$ (two-tailed).

${ }^{b}$ Correlation is trending at $p=0.068$ (two-tailed). 
Table 4. Rank-biserial correlations between ACE-Q items and MIES.

\begin{tabular}{|c|c|c|c|c|}
\hline & MIES total & PCL total & MIES transgressions & MIES betrayals \\
\hline Emotional abuse & $0.469 * *$ & 0.268 & $0.415^{*}$ & $0.397^{*}$ \\
\hline Physical abuse & -0.003 & 0.010 & 0.000 & -0.059 \\
\hline Sexual abuse & 0.037 & -0.033 & 0.186 & -0.149 \\
\hline Emotional neglect & 0.229 & 0.047 & 0.283 & 0.111 \\
\hline Physical neglect & 0.144 & -0.203 & 0.242 & -0.024 \\
\hline Separation/divorce & -0.164 & 0.055 & -0.171 & -0.029 \\
\hline Domestic violence & 0.078 & 0.156 & 0.187 & -0.004 \\
\hline Substance abuse & 0.007 & -0.081 & 0.129 & 0.017 \\
\hline Mental illness & 0.052 & -0.010 & 0.191 & -0.052 \\
\hline Incarceration & 0.188 & 0.078 & 0.250 & 0.072 \\
\hline
\end{tabular}

ACE, Adverse Childhood Experiences Questionnaire; PCL, PTSD Checklist for DSM-5; MIES, Moral Injury Events Scale.

${ }^{*}$ Correlation is significant at the 0.05 level (two-tailed).

**Correlation is significant at the 0.01 level (two-tailed).

\section{Discussion}

Our study is the first to identify an association between self-reported childhood emotional abuse and the endorsement of MI in CAF personnel and veterans. This association remained significant after controlling for age and gender. Here, exposure to ACEs antedated the exposure to MI in adulthood, pointing towards a possible childhood risk factor for the perception of MI over the course of military service. Notably, rates of childhood exposure to emotional abuse (i.e. 48.5\%) among this treatment-seeking inpatient sample of CAF members and veterans exposed to traumatic events were in line with those reported in a larger sample (i.e. Afifi et al., 2016). Moreover, the reported extent of MI on the MIES was high; an average score of 38.0 was reported on this scale, with 54.0 being the upper boundary of the sample, the maximum score one can receive. Taken together, these results not only confirm the high rates of exposure to ACEs among CAF members and veterans, and highlight the presence of $\mathrm{MI}$ in this sample, but also suggest that emotional abuse in childhood may continue to confer risk for the perception of MI into adulthood (Cook et al., 2017; Litz et al., 2009; Iversen et al., 2008; LeardMann et al., 2010). Specifically, individuals who have experienced ACEs, such as childhood emotional abuse, may develop alternative negative beliefs regarding themselves, others, and the world, which may put these individuals at risk for the development of MI (Cook et al., 2017; Litz et al., 2009; Vargas et al., 2013).

\subsection{Comparison to other findings}

In keeping with previous studies (e.g. Currier et al., 2015; Marx et al., 2010; Nazarov et al., 2015), we found significant positive correlations between some, but not all, symptoms of PTSD and MI in a military sample. Here, severity of MIES perceived betrayals was correlated positively with the PCL-5 subscales avoidance and negative alterations in cognition/mood, suggesting that MI is associated with avoidance behaviours, the onset of negative emotions such as guilt and shame, and the inability to experience positive emotion. Critically, this correlation remained significant after controlling for age and gender. It is perhaps unsurprising that MI did not correlate with all PTSD symptoms, as MI captures aspects of traumatic experience outside those defined by the DSM-5's diagnostic criteria of PTSD (Litz et al., 2009; Shay, 2014). Although the DSM-5 PTSD criteria now recognizes negative emotions including guilt, shame, and anger that often accompany MI, it fails to recognize other instances that may have broad adverse mental health sequelae (e.g. experiences that violate deeply held moral values or instances in which an individual perceives themselves to be the 'perpetrator' of an immoral action) (Farnsworth, Drescher, Nieuwsma, Walser, \& Currier, 2014; Litz et al., 2009).

It also is interesting that whereas the betrayal component of MI was significantly associated with some symptoms of PTSD, the transgressions MI scale was not, suggesting that betrayals may play an important role in the relation between MI and PTSD. This finding may be unique to the CAF, where operations, until recently, have placed greater emphasis on peacekeeping, resulting in less exposure to direct combat operations than, for example, its American counterpart (Granatstein, Panneton, \& Foot, 2006, April 29). These operations, for example, in Rwanda, involved exposure to difficult situations where military members were unable to act (e.g. preventing the death of civilians) despite a strong moral prerogative to do so (e.g. Dallaire \& Beardsley, 2003), perhaps resulting in a greater likelihood of perceived betrayal by authority figures providing direction to these operations.

\subsection{Clinical implications}

These findings have important clinical implications. Here, we hypothesize that an emotionally abused child may internalize feelings of guilt and shame, developing a schema such as, 'I'm no good'. Subsequent events in the operational theatre may reactivate these same core beliefs, heightening the risk of $\mathrm{MI}$. 
With respect to treatment, adaptive disclosure (AD) and impact of killing in war (IOK) are two treatment modalities designed to address MI; however, neither of these treatments explores early childhood trauma (Litz et al., 2009; Maguen et al., 2017). Specifically, AD utilizes imaginal exposure in which the patient holds imagined discussions with moral authority figures from their life (Litz et al., 2009). Conversely, IOK utilizes a cognitive-behavioural framework to address attributions related to killing in war (Maguen et al., 2017). The findings of this study suggest that prior to proceeding with treatment of MI, clinicians should screen military members and veterans for instances of ACEs, such as childhood emotional abuse, for appropriate treatment planning. Future research, however, is required to determine how to appropriately incorporate ACEs into the treatment of MI.

Moreover, these findings also have important implications for prevention efforts, where military members exposed to ACEs may benefit from psychoeducation regarding MI and its associated psychological symptoms, which may normalize the reactions of personnel to morally injurious events, allowing them to overcome shame and guilt. This, in turn, may facilitate reporting of these types of events and treatment-seeking behaviours. Notably, some military personnel may feel uncomfortable disclosing morally injurious events owing to perceived violations of the rules of engagement surrounding military operations, and associated legal ramifications, limiting disclosure in some circumstances.

When working clinically with military personnel who have experienced ACEs or who have been exposed to morally injurious events, it is important not to assume that they have developed a MI. In particular, mere exposure to morally injurious events or childhood emotional abuse may not always result in $\mathrm{MI}$, in the same manner in which exposure to trauma does not always lead to PTSD (Santiago et al., 2013). For example, potentially similar to $\mathrm{MI}$, there are many mediating factors, including cognitive appraisals such as negative sense of self, which influence the development of PTSD following trauma (Sheerin et al., 2018). Many individuals may have natural buffers that allow them to process and overcome these events without negative mental health sequelae.

\subsection{Strengths and limitations}

The present study's strengths included having clinicians administer the self-assessment package, so that if distress was provoked by any of the questions, it could be addressed within a therapeutic setting. This also ensured that participants' identity remained unknown to the research team. Our sample is largely representative of the larger CAF, where females represent $14.7 \%$ of the CAF and comprised $12.1 \%$ in our sample. Moreover, $95 \%$ of our sample fell in the age range of $24.1-65.3$ years, where $80.7 \%$ of the CAF fall in this range (Park, 2008). Levels of education were also similar to those reported in the CAF, with $27.3 \%$ of our sample reporting having obtained a high school diploma compared with $28 \%$ of the CAF (Park, 2008).

There are several limitations to the present study. First, the study utilized an inpatient sample where severity of PTSD and MI was high among the majority of individuals and variation between patients was relatively constricted. This contrasts with similar studies involving outpatient samples with large variations in symptom severity on measures of mental illness (e.g. Cabrera et al., 2007; Iversen et al., 2008, 2007; LeardMann et al., 2010). Here, restricted variability due to high symptom scores may have limited the ability of statistical tests to detect correlations, increasing the chance of type II error.

Another limitation of the study was its sample size, which limited the generalizability of our findings to the greater CAF population, and contributed to the non-normal distribution of the variables. As a result, we implemented non-parametric tests, which are known to be less sensitive than tests requiring normality. Despite the restricted power, our key finding of a significant relation between childhood emotional abuse (reported retrospectively) and MI emerged, highlighting the signal strength of this provocative new observation.

Although the retrospective nature of reporting ACEs is a potential limitation of our study, there is little evidence that individuals falsely report (false-positive) ACEs, thus inflating scores on the ACE-Q. Instead, in a meta-analytic report, Hard and Rutter (2004) found that reports of early child adversity are more prone to false negatives than to false positives; individuals are more likely to neglect reporting an ACE that did occur than to falsely report one that did not occur. Hence, although we cannot be certain, an underestimation of ACEs may have occurred in our sample.

In addition, the MIES has been criticized as a measure of MI (Frankfurt \& Frazier, 2016). Specifically, some items on this scale measure exposure to events of a potentially morally injurious nature as opposed to capturing fully psychological response to this exposure (Frankfurt \& Frazier, 2016). Coupling exposure and the effects of this exposure into one score can yield inflated levels of MI (Frankfurt \& Frazier, 2016). Efforts to improve the measurement of MI, such as the Moral Injury Symptoms Scale - Military Version (Koenig et al., 2018), are currently underway.

\subsection{Future directions}

Longitudinal, prospective studies of at-risk populations will provide the strongest evidence for the relation 
between ACEs and the onset of MI in military sample. Studies may examine the severity of MI pre- and postdeployment, and timing of MI events during deployment, to better assess how multiple factors including, ACEs, deployment length, and time since MI event influence the onset of MI. It will also be important to replicate the present findings in a larger sample, according to the sociodemographic distribution of the $\mathrm{CAF}$, allowing for more variation in MI scores - which were high in the present sample - and to obtain results which are more representative of the entire CAF population. Moreover, it will be critical to investigate the generalizability to other populations, including public safety personnel/first responders and journalists, who are also susceptible to exposure to morally injurious events where intervention may be prohibited or impossible (e.g. atrocities and mass accidents). Finally, future studies may examine the efficacy of treatment interventions that incorporate discussion of ACEs.

\section{Conclusions}

The present study highlights the impact that ACEs may continue to exert on mental health outcomes into adulthood. Specifically, self-reported exposure to emotional abuse during childhood was associated with the onset of MI into adulthood among CAF personnel and veterans. These findings point towards the need for early intervention efforts that target specifically the presence of ACEs as a potential risk factor for the development of MI among military personnel and veterans. Accordingly, emerging treatments for MI may consider carefully the impact of ACEs on current interpretations of morally injurious events (e.g. as a lens for interpreting actions of others), and may assist military members and veterans in reframing events from the perspective of a competent adult rather than a vulnerable child. As noted, psychological dysfunction is associated with negative occupational outcomes among military members (Boulos \& Zamorski, 2016; Hoge et al., 2006, 2005). Accordingly, increased identification of risk factors for the development of MI and the development of effective interventions for this psychological injury are expected to reduce attrition and discharge in military populations. Ultimately, these efforts are expected to improve quality of life and functional outcomes (e.g. return to service and transition from military to civilian life) among current CAF members and veterans.

\section{Acknowledgement}

The authors would like to thank the staff at the Program for Traumatic Stress Recovery at Homewood Health Centre and the Homewood Research Institute for their assistance in the collection of these data.

\section{Disclosure statement}

No potential conflict of interest was reported by the authors.

\section{Funding}

This work was supported by a grant from the Canadian Institute for Military and Veteran Health Research [grant number W7714-145967/001/SV] to MCM and RAL; MCM was supported by the Homewood Chair in Mental Health and Trauma at McMaster University; AMB was supported by an undergraduate student research award from McMaster University Faculty of Social Sciences.

\section{ORCID}

Alina Protopopescu (D) http://orcid.org/0000-0001-88960281

Jenna E. Boyd (1) http://orcid.org/0000-0001-8710-2066

Chantelle Lloyd (1) http://orcid.org/0000-0003-2326-7851

Anthony Nazarov (1) http://orcid.org/0000-0002-3288-7609

Ruth A. Lanius (D) http://orcid.org/0000-0002-3758-1393

\section{References}

Afifi, T. O., Taillieu, T., Zamorski, M. A., Turner, S., Cheung, K., \& Sareen, J. (2016). Association of child abuse exposure with suicidal ideation, suicide plans, and suicide attempts in military personnel and the general population in Canada. JAMA Psychiatry, 73(3), 229-238.

American Psychiatric Association. (2013). Diagnostic and statistical manual of mental disorders (5th ed.). Arlington, VA: American Psychiatric Publishing.

Bank, C. T. D. (2013). Adverse experiences: Indicators on children and youth. Bethesda, MD. Retrieved from $h t t p: / /$ www.childtrends.org/wpcontent/uploads/2013/07/124 Adverse_Experiences.pdf

Blevins, C. A., Weathers, F. W., Davis, M. T., Witte, T. K., \& Domino, J. L. (2015). The posttraumatic stress disorder checklist for DSM-5 (PCL-5): Development and initial psychometric evaluation. Journal of Traumatic Stress, 28(6), 489-498.

Blosnich, J. R., Dichter, M. E., Cerulli, C., Batten, S. V., \& Bossarte, R. M. (2014). Disparities in adverse childhood experiences among individuals with a history of military service. JAMA Psychiatry, 71(9), 1041-1048.

Boulos, D., \& Zamorski, M. A. (2016). Military occupational outcomes in Canadian Armed Forces personnel with and without deployment-related mental disorders. The Canadian Journal of Psychiatry, 61(6), 348-357.

Boyd, J. E., Protopopescu, A., O'Connor, C., Neufeld, R. J. W., Jetly, R., Hood, H. K., ... McKinnon, M. C. (2018). Dissociative symptoms mediate the relation between PTSD symptoms and functional impairment in a sample of military members, veterans, and first responders with PTSD. European Journal of Psychotraumatology, 9(1), 1463794.

Cabrera, O. A., Hoge, C. W., Bliese, P. D., Castro, C. A., \& Messer, S. C. (2007). Childhood adversity and combat as predictors of depression and post-traumatic stress in deployed troops. American Journal of Preventive Medicine, 33(2), 77-82.

Cook, A., Spinazzola, J., Ford, J., Lanktree, C., Blaustein, M., Cloitre, M., ... Mallah, K. (2017). Complex trauma 
in children and adolescents. Psychiatric Annals, 35(5), 390-398.

Currier, J. M., Holland, J. M., \& Malott, J. (2015). Moral injury, meaning making, and mental health in returning veterans. Journal of Clinical Psychology, 71(3), 229-240.

Dallaire, R., \& Beardsley, B. (2003). Shake hands with the devil: The failure of humanity in Rwanda. Toronto, ON: Random House.

Farnsworth, J. K., Drescher, K. D., Nieuwsma, J. A., Walser, R. B., \& Currier, J. M. (2014). The role of moral emotions in military trauma: Implications for the study and treatment of moral injury. Review of General Psychology, 18(4), 249.

Felitti, V. J., Anda, R. F., Nordenberg, D., Williamson, D. F., Spitz, A. M., Edwards, ... Marks, J. S. (1998). Relationship of childhood abuse and household dysfunction to many of the leading causes of death in adults: The Adverse Childhood Experiences (ACE) study. American Journal of Preventive Medicine, 14(4), 245-258.

Frankfurt, S., \& Frazier, P. (2016). A review of research on moral injury in combat veterans. Military Psychology, 28 (5), 318-330.

Granatstein, J. L., Panneton, D., \& Foot, R. (2006, April 29). Peacekeeping. The Canadian Encyclopedia. Retrieved from https://www.thecanadianencyclopedia. ca/en/article/peacekeeping.

Hardt, J., \& Rutter, M. (2004). Validity of adult retrospective reports of adverse childhood experiences: Review of the evidence. Journal of Child Psychology and Psychiatry, 45(2), 260-273.

Hoge, C. W., Auchterlonie, J. L., \& Milliken, C. S. (2006). Mental health problems, use of mental health services, and attrition from military service after returning from deployment to Iraq or Afghanistan. JAMA, 295(9), 1023-1032.

Hoge, C. W., Toboni, H. E., Messer, S. C., Bell, N., Amoroso, P., \& Orman, D. T. (2005). The occupational burden of mental disorders in the US military: Psychiatric hospitalizations, involuntary separations, and disability. American Journal of Psychiatry, 162(3), 585-591.

Iversen, A. C., Fear, N. T., Ehlers, A., Hughes, J. H., Hull, L., Earnshaw, M., ... Hotopf, M. (2008). Risk factors for post-traumatic stress disorder among UK Armed Forces personnel. Psychological Medicine, 38(4), 511-522.

Iversen, A. C., Fear, N. T., Simonoff, E., Hull, L., Horn, O., Greenberg, N., ... Wessely, S. (2007). Influence of childhood adversity on health among male UK military personnel. The British Journal of Psychiatry, 191(6), 506-511.

Jordan, A. H., Eisen, E., Bolton, E., Nash, W. P., \& Litz, B. T. (2017). Distinguishing war-related PTSD resulting from perpetration- and betrayal-based morally injurious events. Psychological Trauma: Theory, Research, Practice, and Policy, 9(6), 627.

Katon, J. G., Lehavot, K., Simpson, T. L., Williams, E. C., Barnett, S. B., Grossbard, J. R., ... Reiber, G. E. (2015). Adverse childhood experiences, military service, and adult health. American Journal of Preventive Medicine, 49(4), 573-582.

Koenig, H. G., Ames, D., Youssef, N. A., Oliver, J. P., Volk, F., Teng, E. J., ... Pearce, M. (2018). The Moral Injury Symptom Scale-Military Version. Journal of Religion and Health, 57(1), 249-265.

Lang, A. J., Aarons, G. A., Gearity, J., Laffaye, C., Satz, L., Dresselhaus, T. R., \& Stein, M. B. (2008). Direct and indirect links between childhood maltreatment, posttraumatic stress disorder, and women's health. Behavioral Medicine, 33(4), 125-136.

LeardMann, C. A., Smith, B., \& Ryan, M. A. (2010). Do adverse childhood experiences increase the risk of postdeployment posttraumatic stress disorder in US Marines? BMC Public Health, 10(1), 437.

Litz, B. T., Stein, N., Delaney, E., Lebowitz, L., Nash, W. P., Silva, C., \& Maguen, S. (2009). Moral injury and moral repair in war veterans: A preliminary model and intervention strategy. Clinical Psychology Review, 29(8), 695-706.

Lutz, A. (2008). Who joins the military?: A look at race, class, and immigration status. Journal of Political and Military Sociology, 36(2), 167-188.

Maguen, S., Burkman, K., Madden, E., Dinh, J., Bosch, J., Keyser, J., ... Neylan, T. C. (2017). Impact of killing in war: A randomized, controlled pilot trial. Journal of Clinical Psychology, 73(9), 997-1012.

Marx, B. P., Foley, K. M., Feinstein, B. A., Wolf, E. J., Kaloupek, D. G., \& Keane, T. M. (2010). Combat-related guilt mediates the relations between exposure to combatrelated abusive violence and psychiatric diagnoses. Depression and Anxiety, 27(3), 287-293.

Merrick, M. T., Ports, K. A., Ford, D. C., Afifi, T. O., Gershoff, E. T., \& Grogan-Kaylor, A. (2017). Unpacking the impact of adverse childhood experiences on adult mental health. Child Abuse \& Neglect, 69, 10-19.

Nash, W. P., Marino Carper, T. L., Mills, M. A., Au, T., Goldsmith, A., \& Litz, B. T. (2013). Psychometric evaluation of the moral injury events scale. Military Medicine, 178(6), 646-652.

Nazarov, A., Fikretoglu, D., Liu, A., Thompson, M., \& Zamorski, M. A. (2018). Greater prevalence of posttraumatic stress disorder and depression in deployed Canadian Armed Forces personnel at risk for moral injury. Acta Psychiatrica Scandinavica, 137(4), 342-354.

Nazarov, A., Jetly, R., McNeely, H., Kiang, M., Lanius, R., \& McKinnon, M. C. (2015). Role of morality in the experience of guilt and shame within the armed forces. Acta Psychiatrica Scandinavica, 132(1), 4-19.

Park, J. (2008). A profile of the Canadian Forces. Perspectives, 9(7), 17-30.

Santiago, P. N., Ursano, R. J., Gray, C. L., Pynoos, R. S., Spiegel, D., Lewis-Fernandez, R., ... Fullerton, C. S. (2013). A systematic review of PTSD prevalence and trajectories in DSM-5 defined trauma exposed populations: Intentional and non-intentional traumatic events. PloS One, 8(4), e59236.

Sareen, J., Henriksen, C. A., Bolton, S. L., Afifi, T. O., Stein, M. B., \& Asmundson, G. J. G. (2013). Adverse childhood experiences in relation to mood and anxiety disorders in a population-based sample of active military personnel. Psychological Medicine, 43(1), 73-84.

Shay, J. (1991). Learning about combat stress from Homer's Iliad. Journal of Traumatic Stress, 4(4), 561-579.

Shay, J. (2014). Moral injury. Psychoanalytic Psychology, 31 (2), 182.

Sheerin, C. M., Chowdhury, N., Lind, M. J., Kurtz, E. D., Rappaport, L. M., Berenz, E. C., ... Amstadter, A. B. (2018). Relation between coping and posttrauma cognitions on PTSD in a combat-trauma population. Military Psychology, 30(2), 98-107.

Skopp, N. A., Luxton, D. D., Bush, N., \& Sirotin, A. (2011). Childhood adversity and suicidal ideation in a clinical military sample: Military unit cohesion and intimate relationships as protective factors. Journal of Social and Clinical Psychology, 30(4), 361-377. 
Thompson, M. M., \& Jetly, R. (2014). Battlefield ethics training: Integrating ethical scenarios in high-intensity military field exercises. European Journal of Psychotraumatology, 5(1), 23668.

Turner, S., Taillieu, T., Cheung, K., Zamorski, M., Boulos, D., Sareen, J., \& Afifi, T. O. (2017). Child abuse experiences and perceived need for care and mental health service use among members of the Canadian Armed Forces. The Canadian Journal of Psychiatry, 62(6), 413-421.

Vargas, A., Hanson, T., Kraus, D., Drescher, K., \& Foy, D. (2013). Moral injury themes in combat veterans' narrative responses from the national vietnam veterans' readjustment study. Traumatology, 19(3), 243-250.

Watkins, K., Sudom, K., \& Zamorski, M. (2016). Association of combat experiences with post-traumatic stress disorder among Canadian military personnel deployed in support of the mission in Afghanistan. Military Behavioral Health, 4(3), 285-292.
Weathers, F. W., Litz, B. T., Keane, T. M., Palmieri, P. A., Marx, B. P., \& Schnurr, P. P. (2013). The PTSD Checklist for DSM-5 (PCL-5). Scale available from the National Center for PTSD. Retrieved from https://www.ptsd.va.gov/professional/assess ment/adult-sr/ptsd-checklist.asp.

Weeks, M., Garber, B. G., \& Zamorski, M. A. (2016). Disability and mental disorders in the Canadian Armed Forces. The Canadian Journal of Psychiatry, 61 (Supplement 1), 56S-63S.

Williamson, V., Stevelink, S. A., \& Greenberg, N. (2018). Occupational moral injury and mental health: Systematic review and meta-analysis. The British Journal of Psychiatry, 212(6), 339-346.

Xue, C., Ge, Y., Tang, B., Liu, Y., Kang, P., Wang, M., \& Zhang, L. (2015). A meta-analysis of risk factors for combat-related PTSD among military personnel and veterans. PloS One, 10(3), e0120270. 